\title{
Individual and Occupational Factors Associated With Low Back Pain: The First-ever Occupational Health Study Among Bangladeshi Online Professionals
}

\author{
Mosharop Hossian ${ }^{1,2}$, Mohammad Hayatun Nabi ${ }^{1}$, Ahmed Hossain ${ }^{1}$, Mohammad Delwer Hossain Hawlader ${ }^{1}$, \\ Nadira Sultana Kakoly ${ }^{1}$ \\ ${ }^{1}$ Department of Public Health, North South University, Dhaka, Bangladesh; ${ }^{2}$ Public Health Professional Development Society (PPDS), Dhaka, \\ Bangladesh
}

Objectives: Low back pain (LBP) is a common chronic condition among sedentary workers that causes long-term productivity loss. This study aimed to identify the relationships of individual and occupational factors with LBP among Bangladeshi online professionals. Methods: We conducted a cross-sectional study involving 468 full-time online professionals who usually worked in a sitting position. One-month LBP complaints were assessed using a musculoskeletal subscale of subjective health complaints. The chi-square test was used to measure associations between categorical predictors and LBP, and multivariable logistic regression was conducted to identify the variables significantly associated with LBP.

Results: LBP within the last month was reported by $65.6 \%$ of participants. Multivariable logistic regression analysis indicated that age $>30$ years (adjusted odds ratio [aOR], $0.40 ; 95 \%$ confidence interval $[\mathrm{Cl}], 0.23$ to 0.70 ) and being married (aOR, $0.59 ; 95 \% \mathrm{Cl}, 0.36$ to 0.97) had significant negative associations with LBP. Significant positive associations were found for spending $>50$ hours weekly on average working in a sitting position ( $\mathrm{aOR}, 1.61 ; 95 \% \mathrm{Cl}, 1.05$ to 2.49 ), being overweight and obese (aOR, 1.87; $95 \% \mathrm{Cl}, 1.16$ to 2.99 ), sleeping on a soft mattress (aOR, 2.01; 95\% Cl, 1.06 to 3.80), and ex-smoking status (aOR, 3.33; 95\% $\mathrm{Cl}, 1.41$ to 7.87 ).

Conclusions: A high prevalence of LBP was found among full-time online professionals. Long working hours in a sitting position showed a significant association with developing LBP. Smoking history, body mass index, and sleeping arrangements should also be considered while considering solutions for LBP prevalence among online professionals.

Key words: Online professionals, Low back pain, Occupational health, Bangladesh, Online freelancers

\section{INTRODUCTION}

The systematic analysis of the Global Burden of Diseases

Received: October 19, 2021 Accepted: December 30, 2021

Corresponding author: Mosharop Hossian Public Health Professional Development Society (PPDS), 60 Purbo Tejturi Bazar, Farmgate, Dhaka 1215, Bangladesh E-mail: mosharop.hossian@northsouth.edu

This is an Open Access article distributed under the terms of the Creative Commons Attribution Non-Commercial License (https://creativecommons.org/licenses/by$\mathrm{nc} / 4.0 /$ ) which permits unrestricted non-commercial use, distribution, and reproduction in any medium, provided the original work is properly cited. suggested that among 369 diseases and injuries, low back pain (LBP) is 1 of the top 4 causes of disability-adjusted life-years (DALYs) in the 25-year to 49-year age group [1]. LBP has also become a major cause of productivity loss. For example, between 2012 and 2016, approximately US dollar (USD) 2.2 billion was spent on Brazilian LBP patients, with the highest share attributed to productivity losses [2].

Regular computer users account for a substantial portion of 
individuals affected by LBP. A study conducted among computer-using office workers in Iran found that prolonged computer use led to many health issues, including musculoskeletal disorders [3]. Another study conducted in Lithuania reported that among all types of work-related musculoskeletal disorders, LBP was the most common phenomenon among computer users [4]. Several other studies reported a high prevalence of LBP among computer users who work in a sitting position for long hours. A study conducted among office workers in Turkey who were involved with computer-related tasks found that the 12-month prevalence of LBP was 64.1\% [5]. Another study conducted among public service computer users from Lithuania reported that the 12-month prevalence of LBP was $56.1 \%$ [4].

The digital gig industry has been booming in the last couple of years. According to the Freelancer.com Fast 50 Report for Q3 2020, a 14.0\% rise was observed in online job posts in the third quarter of 2020 [6]. The Oxford Internet Institute reported that Bangladesh is the second-largest supplier of online professionals and that Bangladeshi online professionals are involved with software development, creative and multimedia work, sales and marketing support, writing and translation, data entry, and clerical tasks, among others [7]. The term "onlyne professionals" or commonly known "online freelancers" refers to professionals who serve multiple clients at various hours remotely from their homes/co-working spaces instead of full-time employment at the premises of a single employer [8]. There was a myth that online professionals are occasional workers, but there are now approximately 500000 active workers among an estimated 650000 Bangladeshi online professionals, most of whom are relatively young [9]. In 2019, Bangladeshi online professionals achieved $27.0 \%$ year-on-year revenue growth [10]. However, the sustainability of this potential industry largely depends on the occupational health and safety of the industry's professionals.

Studies around the globe have found that several occupational and individual factors were significantly associated with LBP development. Globally, 37.0\% of LBP cases were attributed to occupational factors [11]. Online professionals usually lead sedentary lifestyles, including long working hours in a sitting position, which is directly correlated with several severe health issues. A recent study suggested that excessive sitting in the same posture, depressed mood, and being female were risk factors for LBP [12]. Another study conducted among bank employees in the city of Dhaka found that increased age, prolonged office working hours, length of employment, comor- bid conditions, and physical activity were significantly associated with LBP complaints [13].

Although several articles have already identified the risk factors of LBP among prolonged computer users, there remains a research gap. To the best of our knowledge, no research has yet been conducted on LBP in the online professional sector in Bangladesh. As online professionals are individual workers who work for clients from different settings, it is difficult to envision that governmental laws alone would suffice to protect their health issues. Instead, introducing health guidelines along with laws and promoting those guidelines among online professionals could be an effective strategy to tackle the burden of LBP among this group. Therefore, the present study focused on quantifying the prevalence of LBP and identifying the associated individual and occupational factors among online professionals in Bangladesh.

\section{METHODS}

\section{Study Site and Study Population}

We conducted a cross-sectional study among Bangladeshi online professionals between May and June 2021. There are around 650000 online professionals in Bangladesh [9]. As they are commonly available through online platforms rather than physical contact, we reached them through their appropriate skillset-based community leaders. People who met the following inclusion and exclusion criteria were eligible for inclusion as study subjects:

\section{Inclusion criteria}

(1) Full-time online professionals who worked for $\geq 35$ hours a week on average as service providers in the global markets of digitally delivered freelance works [14] for at least 1 year. (2) Age: 18-50 years old. (3) Online professionals who primarily worked in a sitting position. (4) Willingness to voluntarily participate in the study.

\section{Exclusion criteria}

(1) Female online professionals who were pregnant or who had a baby less than 6 months of age during the study. (2) Any physical structural deformity (joint or bone disorder or slipped disc). (3) Recent surgery (due to an accident or a pre-existing physical condition) in the pelvis, spine, or lower half of the body. (4) Chronic arthritis in the lower half of the body. 


\section{Sampling Technique and Sample Size}

We used convenience sampling to identify respondents of interest. The minimum required sample size for our study was calculated based on a standard normal variation of 1.96 , a $5 \%$ precision level, and assuming a 56.0\% prevalence of LBP among online professionals [4]. We calculated the minimum required sample as 379 .

We shared the online questionnaire to the online professionals through skill set-based community leaders, such as a web and mobile development community, graphic designers' community, or digital marketing community. During the study period, we received 480 completed responses and excluded 12 duplicated responses by cross-checking basic identifying information. Finally, we included 468 respondents in our analysis.

\section{Dependent variable}

The musculoskeletal subscale of subjective health complaints was used to measure respondents' LBP level in the last 1 month [15]. The respondents were asked to report the presence of pain or discomfort in their lower back with 4 answer options ("no," "mild," "moderate," or "severe"). Respondents who answered "no LBP" were identified as having no LBP problems. Study subjects who answered that they had mild LBP, moderate LBP, or severe LBP were categorized as having the presence of some sort of LBP in the last month.

\section{Independent variables}

Data on socio-demographic variables-age, sex, education, body mass index (BMl; formulated based on respondent's height and weight), and marital status-were collected. Behavioral factors such as smoking status (current, never, or previous), sleep arrangement (firm or soft mattress), and level of physical activity were elicited through the questionnaire. The answer choice (firm/soft) for the sleep arrangement was participants' subjective perception regarding the hardness of the mattress they slept on. The level of physical activity was assessed based on the metabolic-equivalent task (MET) scale. In this current study, we asked about participants' weekly moderate/vigorous activities and walking to measure their physical activity level. We then calculated the MET score based on the International Physical Activity Questionnaire short-form guideline, and the physical activity level was categorized into low, moderate, and high [16]. Data on occupational factors were also collected, including the length of work experience as an online profession- al and average weekly working hours. We also collected data on chronic illnesses (e.g., diabetes, hypertension, or chronic kidney disease) of our study participants.

\section{Statistical Analysis}

Stata version 15 for Mac (StataCorp., College Station, TX, USA) was used to analyze the data. We presented descriptive statistics (frequencies and percentages) of the categorical variables according to the presence or absence of LBP. A graphical pie chart was used to display the distribution of different levels of LBP among online professionals. The chi-square test was conducted to compare different categorical variables according to the presence or absence of LBP. We also conducted a binary multivariable logistic regression model analysis considering LBP status as the dependent variable and adjusted for the variables contained in Tables 1 and 2 using the enter method. The independent variables for the multiple regression model were chosen based on the previous literature and biological importance. Adjusted odds ratios (aORs) were calculated for each factor in the model and considered statistically significant at a $5 \%$ significance level.

Table 1. Univariate analysis: socio-demographic characteristics of the study participants

\begin{tabular}{|c|c|c|c|c|}
\hline \multirow{2}{*}{ Characteristics } & \multicolumn{2}{|c|}{ Presence of LBP } & \multirow{2}{*}{ Total } & \multirow{2}{*}{$p$-value } \\
\hline & Yes & No & & \\
\hline Age (y) & & & & 0.008 \\
\hline$\leq 30$ & 247 (68.8) & 112 (31.2) & $359(76.7)$ & \\
\hline$>30$ & $60(55.0)$ & $49(45.0)$ & $109(23.3)$ & \\
\hline Sex & & & & 0.190 \\
\hline Female & 18 (78.3) & $5(21.7)$ & $23(4.9)$ & \\
\hline Male & $289(64.9)$ & $156(35.1)$ & $445(95.1)$ & \\
\hline Body mass index & & & & 0.266 \\
\hline Healthy & $87(60.4)$ & 57 (39.6) & 144 (30.8) & \\
\hline Underweight & 18 (64.3) & $10(35.7)$ & $28(6.0)$ & \\
\hline Overweight and obese & 202 (68.2) & $94(31.8)$ & $296(63.2)$ & \\
\hline Marital status & & & & 0.096 \\
\hline Unmarried & 181 (68.8) & $82(31.2)$ & $263(56.2)$ & \\
\hline Married & $126(61.5)$ & $79(38.5)$ & $205(43.8)$ & \\
\hline Education & & & & 0.987 \\
\hline $\begin{array}{l}\text { Secondary school } \\
\text { certificate/equivalent }\end{array}$ & $8(61.5)$ & $5(38.5)$ & $13(2.8)$ & \\
\hline HSC/diploma & $81(66.4)$ & $41(33.6)$ & $122(26.1)$ & \\
\hline Graduate & $141(65.6)$ & $74(34.4)$ & $215(45.9)$ & \\
\hline Postgraduate & $77(65.3)$ & $41(34.7)$ & $118(25.2)$ & \\
\hline
\end{tabular}

LBP, low back pain; HSC, higher secondary certificate.

${ }^{1}$ Chi-square test. 
Table 2. Univariate analysis of the associations of behavioral, clinical, and occupational factors with LBP

\begin{tabular}{|c|c|c|c|c|}
\hline \multirow[b]{2}{*}{ Variables } & \multicolumn{2}{|c|}{ Presence of LBP } & \multirow{2}{*}{$\begin{array}{c}\text { Total }(\%) \\
\text { within } \\
\text { categories }\end{array}$} & \multirow[b]{2}{*}{$p$-value ${ }^{1}$} \\
\hline & $\begin{array}{c}\text { Yes } \\
\text { n (row \%) }\end{array}$ & $\begin{array}{c}\text { No } \\
\text { n (row \%) }\end{array}$ & & \\
\hline Sleeping arrangement & & & & 0.061 \\
\hline Firm & $257(63.9)$ & $145(36.1)$ & 402 (85.9) & \\
\hline Soft & $50(75.8)$ & $16(24.2)$ & $66(14.1)$ & \\
\hline Smoking status & & & & 0.087 \\
\hline Never & $196(64.5)$ & $108(35.5)$ & $304(64.9)$ & \\
\hline Current & $77(63.1)$ & $45(36.9)$ & $122(26.1)$ & \\
\hline Past & $34(81.0)$ & $8(19.0)$ & $42(9.0)$ & \\
\hline Chronic illness & & & & 0.323 \\
\hline No & $248(64.6)$ & $136(35.4)$ & $384(82.1)$ & \\
\hline Yes & $59(70.2)$ & $25(29.8)$ & $84(17.9)$ & \\
\hline Physical activity & & & & 0.978 \\
\hline Low & $186(65.7)$ & $97(34.3)$ & $283(60.5)$ & \\
\hline Moderate & $68(66.0)$ & $35(34.0)$ & $103(22.0)$ & \\
\hline High & $53(64.6)$ & $29(35.4)$ & $82(17.5)$ & \\
\hline Length of work experien & e (y) & & & 0.414 \\
\hline$\leq 5$ & $208(64.4)$ & $115(35.6)$ & $323(69.0)$ & \\
\hline$>5$ & 99 (68.3) & $46(31.7)$ & $145(31.0)$ & \\
\hline Working time (hr/wk) & & & & 0.020 \\
\hline$\leq 50$ & 172 (61.4) & $108(38.6)$ & $280(59.8)$ & \\
\hline$>50$ & 135 (71.8) & $53(28.2)$ & $188(40.2)$ & \\
\hline
\end{tabular}

LBP, low back pain.

${ }^{1}$ Chi-square test.

\section{Ethics Statement}

The study was approved by the Ethical Review Committee (ERC) of North South University, Bangladesh. We followed the guidelines outlined in the Declaration of Helsinki. We also obtained informed consent from each participant during the data collection procedure.

\section{RESULTS}

In total, 468 respondents were included in the study. The participants comprised online professionals of various sociodemographic backgrounds in terms of age, sex, BMI, marital status, and education, and they had different levels of LBP complaints. Overall, $53.6 \%$ of the respondents $(n=251)$ had mild LBP in the last month before the study, $10.3 \%(n=48)$ had moderate LBP, and $1.7 \%(n=8)$ had severe LBP (Figure 1$)$.

Among the 468 respondents, there were 445 (95.1\%) male and 23 (4.9\%) female. The descriptive statistics of the sociodemographic characteristics, such as age, sex, BMI, marital sta-

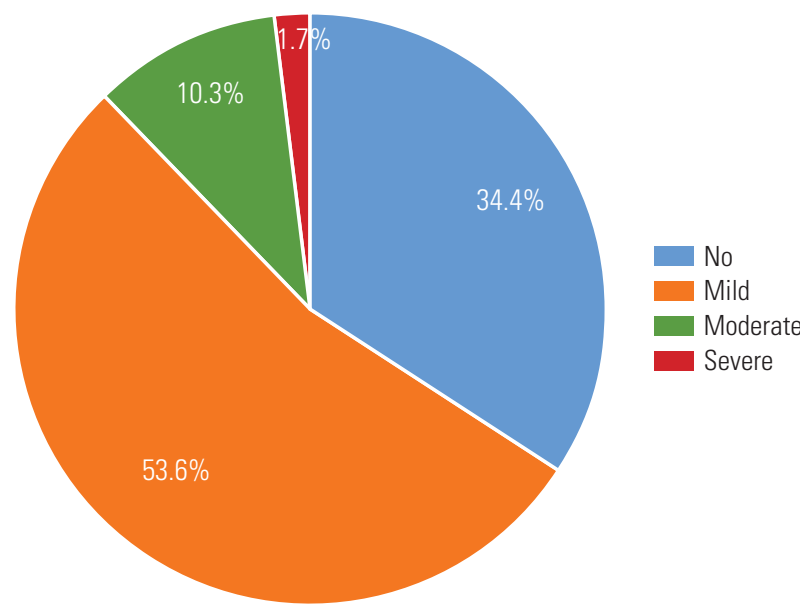

Figure 1. Distribution of low back pain among Bangladeshi online professionals.

tus, education, and sleeping arrangements, are presented in Table 1. Nearly three-fourths $(n=359,76.7 \%)$ of the study participants were under 30 years of age, more than half of the respondents were unmarried ( $n=263,56.2 \%)$, around $70 \%$ $(n=333)$ of the study subjects had at least a graduate level of education, and about $63 \%(n=296)$ of the online professionals were either overweight or obese. The chi-square statistic $p$ value, as shown in Table 1, indicated that age was significantly associated with $\operatorname{LBP}(p=0.008)$.

The individual and occupational factors of the study participants, such as sleeping arrangement, smoking status, chronic illness, physical activity level, length of work experience as online professionals (years), and mean working hours per week, are described in Table 2. Nevertheless, those who worked long hours in a sitting position (on average more than $50 \mathrm{hr} / \mathrm{wk}$ ) more frequently reported LBP than professionals who worked on average less than $50 \mathrm{hr} / \mathrm{wk}$ in a sitting position $(71.8 \%$ and $61.4 \%$, respectively). Similarly, we received more LBP complaints from respondents who had been in the industry for more than 5 years, although the difference was not significant. In terms of smoking status, the highest proportion of LBP complaints was obtained from past smokers ( $n=34,81.0 \%)$, followed by never-smokers ( $n=196,64.5 \%)$ and current smokers ( $n=77,63.1 \%)$. Likewise, soft mattress users ( $n=50,75.8 \%$ ) reported a higher LBP prevalence than firm mattress users $(n=257,63.9 \%)$. Moreover, $70.2 \%(n=59)$ of respondents with any chronic disease (e.g., diabetes, hypertension, or chronic kidney disease) reported the presence of LBP in the last month before the study, whereas the proportion was lower among 
Table 3. Results of multivariable logistic regression for individual and occupational factors associated with LBP

\begin{tabular}{|c|c|c|}
\hline Variables & OR (95\% CI) & aOR (95\% CI) \\
\hline \multicolumn{3}{|l|}{ Age (y) } \\
\hline$\leq 30$ & 1.00 (reference) & 1.00 (reference) \\
\hline$>30$ & $0.56(0.36,0.86)^{*}$ & $0.40(0.23,0.70)^{*}$ \\
\hline \multicolumn{3}{|l|}{ Sex } \\
\hline Female & 1.00 (reference) & 1.00 (reference) \\
\hline Male & $0.51(0.19,1.41)$ & $0.34(0.12,1.00)$ \\
\hline \multicolumn{3}{|l|}{ Body mass index } \\
\hline Healthy & 1.00 (reference) & 1.00 (reference) \\
\hline Underweight & $1.18(0.51,2.74)$ & $1.08(0.45,2.61)$ \\
\hline Overweight and obese & $1.41(0.93,2.13)$ & $1.87(1.16,2.99)^{*}$ \\
\hline \multicolumn{3}{|l|}{ Marital status } \\
\hline Unmarried & 1.00 (reference) & 1.00 (reference) \\
\hline Married & $0.72(0.49,1.06)$ & $0.59(0.36,0.97)^{*}$ \\
\hline \multicolumn{3}{|l|}{ Education } \\
\hline $\begin{array}{l}\text { Secondary school certificate } \\
\text { or equivalent }\end{array}$ & 1.00 (reference) & 1.00 (reference) \\
\hline Higher secondary or diploma & $1.23(0.38,4.01)$ & $1.43(0.41,4.92)$ \\
\hline Graduate & $1.19(0.38,3.77)$ & $1.38(0.41,4.69)$ \\
\hline Postgraduate & $1.17(0.36,3.82)$ & $1.71(0.47,6.14)$ \\
\hline \multicolumn{3}{|l|}{ Sleeping arrangement } \\
\hline Firm & 1.00 (reference) & 1.00 (reference) \\
\hline Soft & $1.76(0.97,3.21)$ & $2.01(1.06,3.80)^{*}$ \\
\hline \multicolumn{3}{|l|}{ Smoking status } \\
\hline Never & 1.00 (reference) & 1.00 (reference) \\
\hline Current & $0.94(0.61,1.46)$ & $1.05(0.65,1.67)$ \\
\hline Past & $2.34(1.05,5.24)^{*}$ & $3.33(1.41,7.87)^{*}$ \\
\hline \multicolumn{3}{|l|}{ Chronic disease } \\
\hline No & 1.00 (reference) & 1.00 (reference) \\
\hline Yes & $1.29(0.78,2.16)$ & $1.41(0.81,2.47)$ \\
\hline \multicolumn{3}{|l|}{ Physical activity } \\
\hline High & 1.00 (reference) & 1.00 (reference) \\
\hline Moderate & $1.06(0.58,1.96)$ & $0.85(0.45,1.63)$ \\
\hline Low & $1.05(0.63,1.76)$ & $0.76(0.44,1.34)$ \\
\hline \multicolumn{3}{|l|}{ Length of work experience (y) } \\
\hline$\leq 5$ & 1.00 (reference) & 1.00 (reference) \\
\hline$>5$ & $1.19(0.78,1.81)$ & $1.47(0.90,2.42)$ \\
\hline \multicolumn{3}{|l|}{ Working time (hr/wk) } \\
\hline$\leq 50$ & 1.00 (reference) & 1.00 (reference) \\
\hline$>50$ & $1.60(1.07,2.38)^{*}$ & $1.61(1.05,2.49)^{*}$ \\
\hline
\end{tabular}

LBP, low back pain; $\mathrm{OR}$, odds ratio; $\mathrm{aOR}$, adjusted odds ratio; $\mathrm{Cl}$, confidence interval.

${ }^{*} p<0.05$.

respondents who had no chronic disease $(n=248,64.6 \%)$. The chi-square statistic $p$-value, as shown in Table 2, indicated that working hours per week were significantly associated with
$\operatorname{LBP}(p=0.020)$

As shown in Table 3, several factors were significantly associated with LBP, as follows: working more than 50 hours on average in a sitting position per week (aOR, 1.61; 95\% confidence interval [CI], 1.05 to 2.49), age more than 30 years (aOR, 0.40 ; $95 \% \mathrm{Cl}, 0.23$ to 0.70 ), the BMl category of overweight and obese (aOR, 1.87, 95\% Cl, 1.16 to 2.99), being married (aOR, $0.59 ; 95 \% \mathrm{Cl}, 0.36$ to 0.97 ), using a soft mattress (aOR, 2.01, $95 \% \mathrm{Cl}, 1.06$ to 3.80 ) and ex-smoking status (aOR, 3.33; 95\% $\mathrm{Cl}, 1.41$ to 7.87$)$.

\section{DISCUSSION}

Around two-thirds of online professionals reported the presence of LBP in this study. Our finding is consistent with other studies conducted among computer users who spend long hours in a sitting position $[17,18]$. Our study results also indicate that long working hours in a sitting position and BMI (overweight/obese) were significant risk factors for LBP. A study conducted among bankers in Dhaka also found that employees who worked long hours in a sitting position reported LBP at a higher rate than those who spent less time in a sitting position [13]. Another study conducted in Australia with office computer workers also reported a similar finding regarding prolonged sitting [19].

Our analyses revealed that age was significantly associated with $L B P$, and online professionals who were more than 30 years old reported proportionately fewer LBP complaints than younger ones. In line with our finding, Sternbach [20] reported that younger adults were at higher risk of experiencing pain of all types (except joint pain) than older adults. A similar result, specifically regarding LBP, was also reported by the South Manchester Back Pain Survey [21]. Although most back pain studies reported a high prevalence of severe LBP among older people, the association between back pain and age was more scattered than is usually believed [22]. The decrease in LBP (especially, low-intensity pain) among older people may be due to various reasons such as cognitive loss, a reduced sense of pain, and greater pain tolerance [22]. According to our findings, only $32.1 \%$ of online professionals of more than 30 years of age worked more than $50 \mathrm{hr} / \mathrm{wk}$ in a sitting position. In contrast, $42.6 \%$ of online professionals of under 30 years old worked more than $50 \mathrm{hr} / \mathrm{wk}$ in a sitting position. The difference in weekly working hours may be because more senior online professionals might generate enough revenue by working compara- 
tively fewer hours per week due to their experience. This difference in weekly working hours might be a reason for the lower prevalence of LBP among online professionals who were more than 30 years old. In our study, this tendency also could have been due to better compliance with recommended health guidelines (e.g., firm mattress use) among older participants.

A negative association was found between the marital status of the study respondents and the presence of LBP. This finding is opposed to the result reported by a study conducted among Chinese computer-using office workers [23]. In our case, the possibility of being married was higher among older participants. The presence of a person to look after them and keep them organized might have been a possible reason for the negative association between marital status and LBP. Respondents who were relatively young were mostly unmarried and reported working long hours, which could be a possible reason for developing LBP.

We also noted a significant positive association between BMI (overweight, obese) and the presence of LBP. A cross-sectional study among adults in the United States suggested that overweight and obesity were associated with increased odds of LBP [24]. LBP may be aggravated among overweight and obese people because their extra weight pulls the pelvis forward and generates extra pressure on the lower back. Among our respondents, it appeared that online professionals who had formerly smoked were more likely to report LBP. Similarly, a British national survey found that ex-smokers had a higher risk for LBP than never-smokers [25]. However, we did not collect data on when the ex-smokers had quit smoking and how long they had smoked; thus, the duration of abstinence from nicotine, a medically relevant factor, was unknown. For this reason, it is not possible to directly comment on how ex-smoking status is linked to the higher prevalence of LBP.

In our study, soft mattress users complained more regarding the presence of LBP than firm mattress users. Research conducted by Koul et al. [26] reported that using soft mattresses for sleeping was significantly associated with the appearance of back pain, which is in line with our results. A possible explanation for this finding is that, - unlike soft mattresses, firm mattresses may help alleviate back pain by distributing the body's weight more equally and supporting spinal alignment.

Our study furnishes evidence that online professionals are highly prone to develop LBP. Although several laws protect the health of different occupational groups, including sedentary workers, in various countries [27-29], online professionals are not included. In Bangladesh, the 2006 Labor Act (amended in 2018) is the primary legislation governing occupational health and safety $[30,31]$. Several other regulations also include provisions related to workplace health and safety. However, the current regulatory framework for occupational safety and health (OSH) in Bangladesh applies mainly to industrial employees and does not address all sectors. Moreover, worker and industry standards are often not maintained due to the lack of enforcement of $\mathrm{OSH}$ regulations [32].

The Philippines recently approved the Freelance Workers Protection Act [33], which includes provisions related to mandatory written contracts, night shift differentials, and hazard pay for online professionals. However, there is no explicit mention of the health and safety of online professionals. In addition, as most online professionals are independent workers and they do not work in organizational settings, it is very challenging to protect their health and ensure long-term productivity just by approving laws.

A recent study conducted among female garment workers in Bangladesh reported a lower prevalence of any musculoskeletal disorders among OSH-compliant factory workers than among non-OSH-compliant factory workers. That study also suggested that working in an OSH-compliant garment factory was a protective factor against the development of musculoskeletal disorders [34]. In our opinion, it is also necessary to encourage workers to comply with $\mathrm{OSH}$ regulations to achieve better results. Another randomized controlled trial conducted among physicians and employees of the Netherlands showed that occupational health practice guideline-based care resulted in better sedentary behavior at the workplace [35].

Taken together, our study findings could provide important materials for public health professionals and policymakers to develop policies and propose health practice guidelines for online professionals.

\section{Strength and Limitations}

The main strength of the study is its novelty. It is the first-ever study on the health issues of Bangladeshi online professionals. However, this study has several limitations. First, the crosssectional nature of the study did not allow us to establish causation between outcome and independent variables. Second, self-administered responses are always susceptible to some degree of responder bias and/or recall bias; however, we used questionnaires designed based on validated tools to reduce these types of biases. Third, responses to some items of the 
questionnaire were subjective as we did not use any instrument in our study to obtain objective measurements of pain level, sitting hours, duration of work experience, or chronic disease complaints. We were also not able to collect data physically due to the global coronavirus disease 2019 pandemic, which may be counted as a limitation of the study. Moreover, since we used convenience sampling, we cannot conclude that our sample represents the whole community.

\section{CONFLICT OF INTEREST}

The authors have no conflicts of interest associated with the material presented in this paper.

\section{FUNDING}

None.

\section{ACKNOWLEDGEMENTS}

We would like to acknowledge the contributions of Mr. Taposh Ghosh (CEO, SERPKey), Mr. Faisal Mustafa (CEO, VISER X), and Mr. Saidur Mamun Khan (Head of Data Operations, Category Marketing, Upwork) for their fantastic collaboration throughout the data collection period.

\section{AUTHOR CONTRIBUTIONS}

Conceptualization: Hossian M, Hossain A, Kakoly NS. Data curation: Hossian M. Formal analysis: Hossian M, Nabi MH. Funding acquisition: None. Methodology: Nabi MH. Project administration: Hawlader MDH, Kakoly NS. Visualization: Hawlader MDH. Writing - original draft: Hossian M, Kakoly NS. Writing review \& editing: Hossain A, Nabi MH, Hawlader MDH.

\section{ORCID}

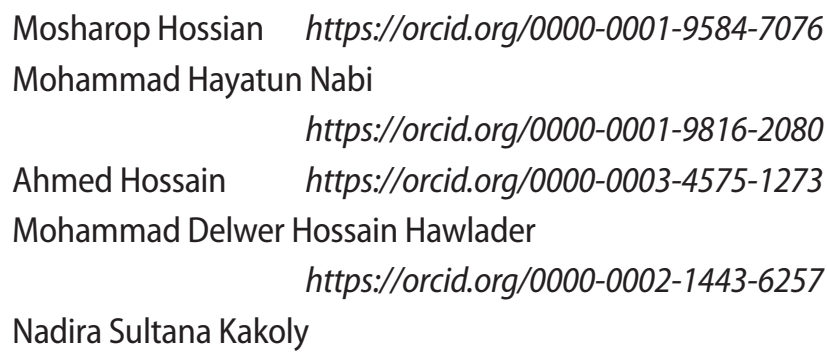

https://orcid.org/0000-0002-2794-8219

\section{REFERENCES}

1. GBD 2019 Diseases and Injuries Collaborators. Global burden of 369 diseases and injuries in 204 countries and territories, 1990-2019: a systematic analysis for the Global Burden of Disease Study 2019. Lancet 2020;396(10258):1204-1222.

2. Carregaro RL, Tottoli CR, Rodrigues DD, Bosmans JE, da Silva EN, van Tulder M. Low back pain should be considered a health and research priority in Brazil: lost productivity and healthcare costs between 2012 to 2016. PLoS One 2020;15(4):e0230902.

3. Alavi SS, Abbasi M, Mehrdad R. Risk factors for upper extremity musculoskeletal disorders among office workers in Qom Province, Iran. Iran Red Crescent Med J 2016;18(10):e29518.

4. Kaliniene G, Ustinaviciene R, Skemiene L, Vaiciulis V, Vasilavicius $P$. Associations between musculoskeletal pain and workrelated factors among public service sector computer workers in Kaunas County, Lithuania. BMC Musculoskelet Disord 2016; 17(1):420.

5. Basakci Calik B, Yagci N, Oztop M, Caglar D. Effects of risk factors related to computer use on musculoskeletal pain in office workers. Int J Occup Saf Ergon 2020. doi: https://doi.org/10.1 080/10803548.2020.1765112.

6. Freelancer.com. Fast 50 Report Q1 2020. Freelance labor demands increase as employment trends shift from strong global economy to impact of Covid-19; 2020 May 14 [cited 2021 Jul 31]. Available from: https://s3.amazonaws.com/press.freelancer.com/Fast\%2050\%20Q1\%202020\%20\%281\%29.pdf.

7. Lehdonvirta V. Where are online workers located? The international division of digital gig work; 2017 [cited 2021 Jul 31]. Available from: https://www.oii.ox.ac.uk/news-events/news/ where-are-online-workers-located-the-international-divisionof-digital-gig-work/.

8. Oxford Internet Institute. How big is the online labour workforce? Our data-driven approach to this tricky question [cited 2021 Sep 10]. Available from: https://ilabour.oii.ox.ac.uk/howmany-online-workers/.

9. Struggles of being a freelancer in Bangladesh. Daily Star; 2021 Apr 16 [cited $2021 \mathrm{Jul}$ 31]. Available from: https://www.thedailystar.net/toggle/news/struggles-being-freelancer-bangladesh-2078253.

10. Friedman K. These 10 countries are the clear-cut capitals of freelancing; 2019 [cited 2021 Jul 31]. Available from: https:// blog.payoneer.com/freelancers/industry-tips-fl/6-countriescapitals-freelancing/.

11. Punnett L, Prüss-Utün A, Nelson DI, Fingerhut MA, Leigh J, Tak 
$\mathrm{S}$, et al. Estimating the global burden of low back pain attributable to combined occupational exposures. Am J Ind Med 2005;48(6):459-469.

12. Hanna F, Daas RN, El-Shareif TJ, Al-Marridi HH, Al-Rojoub ZM, Adegboye OA. The relationship between sedentary behavior, back pain, and psychosocial correlates among university employees. Front Public Health 2019;7:80.

13. Ali M, Ahsan GU, Hossain A. Prevalence and associated occupational factors of low back pain among the bank employees in Dhaka City. J Occup Health 2020;62(1):e12131.

14. U.S. Bureau of Labor Statistics. Labor force statistics from the current population survey [cited 2021 Aug 1]. Available from: https://www.bls.gov/cps/definitions.htm.

15. Eriksen HR, Ihlebaek C, Ursin H. A scoring system for subjective health complaints (SHC). Scand J Public Health 1999;27(1):63-72.

16. International Physical Activity Questionnaire (IPAQ). IPAQ scoring protocol [cited 2021 Aug 1]; Available from: https://sites. google.com/site/theipaq/scoring-protocol.

17. Abaraogu UO, Okorie PN, Duru DO, Ezenwankwo EF. Individual and work-related risk factors for musculoskeletal pain among computer workers in Nigeria. Arch Environ Occup Health 2018; 73(3):162-168

18. Campos-Fumero A, Delclos GL, Douphrate DI, Felknor SA, Vargas-Prada S, Serra C, et al. Low back pain among office workers in three Spanish-speaking countries: findings from the CUPID study. Inj Prev 2017;23(3):158-164.

19. Baker R, Coenen P, Howie E, Williamson A, Straker L. The short term musculoskeletal and cognitive effects of prolonged sitting during office computer work. Int J Environ Res Public Health 2018;15(8):1678.

20. Sternbach RA. Survey of pain in the United States: the Nuprin pain report. Clin J Pain 1986;2(1):49-53.

21. Papageorgiou AC, Croft PR, Ferry S, Jayson MI, Silman AJ. Estimating the prevalence of low back pain in the general population. Evidence from the South Manchester Back Pain Survey. Spine (Phila Pa 1976) 1995;20(17):1889-1894.

22. Dionne CE, Dunn KM, Croft PR. Does back pain prevalence really decrease with increasing age? A systematic review. Age Ageing 2006;35(3):229-234.

23. Ye $S$, Jing $Q$, Wei $C$, Lu J. Risk factors of non-specific neck pain and low back pain in computer-using office workers in China: a cross-sectional study. BMJ Open 2017;7(4):e014914.

24. Peng T, Pérez A, Pettee Gabriel K. The association among overweight, obesity, and low back pain in U.S. adults: a cross-sectional study of the 2015 National Health Interview Survey. J
Manipulative Physiol Ther 2018;41(4):294-303.

25. Palmer KT, Syddall H, Cooper C, Coggon D. Smoking and musculoskeletal disorders: findings from a British national survey. Ann Rheum Dis 2003;62(1):33-36.

26. Koul PA, Bhat MH, Lone AA, Koul AN, Wahid A. The foam mattress-back syndrome. J Assoc Physicians India 2000;48(9):901902.

27. Health and Safety Executive (HSE). Working safely with display screen equipment [cited 2021 Nov 22]. Available from: https://www.hse.gov.uk/msd/dse/.

28. Workplace Health and Safety Queensland. Work health and safety laws [cited 2021 Nov 22]. Available from: https://www. worksafe.qld.gov.au/laws-and-compliance/work-health-andsafety-laws.

29. Laws \& Regulations Database of The Republic of China. Occupational Safety and Health Act [cited 2021 Nov 22]. Available from: https://law.moj.gov.tw/ENG/LawClass/LawAll.aspx? pcode $=$ N0060001.

30. Ministry of Public Administration Government of the People's Republic of Bangladesh. The Bangladesh Labour Act, 2006: Act No. XLII of 2006 [cited 2021 Nov 22]. Available from: https:// www.dpp.gov.bd/upload_file/gazettes/14212_75510.pdf.

31. Ministry of Public Administration Government of the People's Republic of Bangladesh. Bangladesh Labour Law; 2018 [cited 2021 Nov 22]. Available from: https://dife.portal.gov.bd/sites/ default/files/files/dife.portal.gov.bd/law/267e65d1_08ea_4d de_8a5c_82ee1a49b7d6/Labour_Law(Amendment)2018.pdf (Bengali).

32. Bangladesh Institute of Labour Studies (BILS). Occupational safety and health in Bangladesh: national profile; 2015 [cited 2021 Nov 22]. Available from: http://bilsbd.org/wp-content/ uploads/2016/03/BILS-ILO-Study_OSH-Profile_Final-Report_ 29-June-2015.pdf.

33. Republic of the Philippines. Freelance Workers Protection Act [cited 2021 Nov 22]. Available from: https://www.congress. gov.ph/legisdocs/third_18/HBT8817.pdf.

34. Nabi MH, Kongtip P, Woskie S, Nankongnab N, Sujirarat D, Chantanakul S. Factors associated with musculoskeletal disorders among female readymade garment workers in Bangladesh: a comparative study between OSH compliant and non-compliant factories. Risk Manag Healthc Policy 2021;14:1119-1127.

35. Verweij LM, Proper KI, Weel AN, Hulshof CT, van Mechelen W. The application of an occupational health guideline reduces sedentary behaviour and increases fruit intake at work: results from an RCT. Occup Environ Med 2012;69(7):500-507. 